\title{
APLICABILIDADE DA LEI ESTRANGEIRA: REENVIO E REFORMA DA LEI DE INTRODUÇÃO AO CÓDIGO CIVIL BRASILEIRO
}

Juliana Marcondes Vianna ${ }^{1}$

\section{RESUMO}

A aplicabilidade da lei estrangeira implica em alguns questionamentos: pode ocorrer através de uma referência material, feita apenas às normas de direito material, ou através de uma referência global, que engloba as normas de conflito estrangeiras. Da análise das regras de conflito estrangeiras, a regulação da situação privada internacional pode ser devolvida à lei do foro (reenvio de primeiro grau ou retorno) ou enviada a uma terceira lei (reenvio de segundo grau ou transmissão). O Brasil não adota o reenvio. Necessária se faz a reforma da Lei de Introdução ao Código Civil, para que nela se inclua a possibilidade do reenvio como um método orientador, flexível e condutor à tutelar as expectativas dos indivíduos envolvidos em uma relação jurídica plurilocalizada.

Palavras Chave: Regras de Conflito. Reenvio. Projeto de Lei n 4905/1995.

\section{ABSTRACT}

The conflict rules referring to the multiconnected foreign law relation regulation may concern to it by either requesting it to be pertained through material reference, being done merely to the material norms or through a global reference, which includes the foreign Private International Law norms. From the foreign conflict rules analysis, the regulation of the international private situation can be brought back to the lex fori (renvoi of first degree or return) or sent to a third law (renvoi of second degree or transmission). Brazil doesn't adopt the

\footnotetext{
${ }^{1}$ Advogada associada ao escritório Katzwinkel e Advogados Associados, Bacharel em Direito pela Universidade Federal do Paraná com Extensão Universitária pela Faculdade de Direito da Universidade de Lisboa, Portugal. Pós-Graduanda em Direito Civil e Processo Civil pelo Centro Universitário Curitiba.
}

Revista Brasileira de Direito Internacional, Curitiba, v.7, n.7, jan./jun.2008 
renvoi. The need to make the Introduction Law to the Civil Code over, so that the renvoi possibility is included in it. In the Brazilian juridic regulation, the renvoi has got to be comprehended as a guiding, flexible, conveying method which meets the expectations of the involved individuals in the plurilocated juridic relation.

Key words: Conflict Rules. Renvoi. Bill number 4905/1995.

\section{INTRODUÇÃO}

Ao final das tardes das segundas-feiras do ano de 2008, a sala 200 do prédio da Faculdade de Direito da Universidade Federal do Paraná reuniu acadêmicos de direito e profissionais interessados em trocar idéias relativas à temática do comércio internacional.

A primeira vista, pode-se pensar que discutir comércio internacional é debater temas áridos, impessoais e distantes de nossa realidade. Ledo engano. Os debates foram além da objetividade das tratativas comerciais. Avaliamos conseqüências, problemas e dificuldades. Tivemos dúvidas. Questionamos métodos. Investigamos. Refletimos. Ponderamos.

A premissa de que partimos foi nítida: a sociabilidade dos indivíduos não se restringe às fronteiras do Estado soberano à que pertencem. Por razões culturais, políticas e econômicas se estabelecem vínculos com outras realidades culturais e conseqüentemente, outros ordenamentos jurídicos.

Verifica-se, de forma cada vez mais acentuada, a crescente internacionalização das relações sociais, decorrente dos intensos movimentos migratórios, do avanço da tecnologia e do incremento do comércio internacional ${ }^{2}$.

Constatamos que, na maioria das tratativas comerciais internacionais da contemporaneidade, é comum que as partes elejam a lei ou fonte normativa aplicável em caso de controvérsias. Mas e se uma lei estrangeira for escolhida e sua aplicação couber ao Poder Judiciário brasileiro, qual será a extensão de

\footnotetext{
2 PINHEIRO, Luís de Lima. Direito Internacional Privado. Introdução e Direito de Conflitos. 3.ed., v.1. Parte Geral. Coimbra: Editora Almedina, 2006, p. 16.
}

Revista Brasileira de Direito Internacional, Curitiba, v.7, n.7, jan./jun.2008 
sua aplicabilidade? Aplicar-se-á somente as normas de direito material ou também as regras de conflito estrangeiras?

Infelizmente, nosso arcabouço legislativo em matéria de lei aplicável apresenta ainda, alternativas pouco adequadas à tutela efetiva das relações privadas internacionais.

O presente artigo destina-se, portanto, à um despertar. Um despertar que, longe de exaurir a temática concernente à todos os novos debates pertinentes ao comércio internacional, pretende suscitar uma discussão pontual, nascida da leitura de uma lei próxima e pouco utilizada - porque já defasada - nas relações privadas internacionais: a Lei de Introdução ao Código Civil (Decreto Lei № 4657, de 4 de setembro de 1942).

O ordenamento jurídico brasileiro veda, através do disposto no Artigo 16 da Lei de Introdução ao Código Civil, um método valioso para aplicação da lei adequada a tutelar uma relação privada internacional: o reenvio.

Este estudo buscará apresentar o reenvio, questioná-lo e finalmente sugeri-lo como um instrumento hábil a assegurar princípios importantes à tutela das relações privadas internacionais: a aplicação de uma lei próxima às partes interessadas e a harmonia internacional dos julgados.

\section{PRINCÍPIOS ASSEGURADOS PELO REENVIO}

O problema da determinação da lei aplicável, objeto do Direito Internacional Privado, faz com que as relações jurídicas plurilocalizadas, por pertencerem a diversos espaços legislativos, tragam uma situação de instabilidade. ${ }^{3}$ O Direito Internacional Privado tem por finalidade reduzir esta instabilidade através das regras de determinação da lei aplicável. Referidas regras devem, através da escolha de um elemento de conexão relevante entre as duas ordens jurídicas conflitantes, atentarem para alguns princípios.

Para que o reenvio, objeto do presente estudo, seja adequadamente compreendido, a análise prévia de certos princípios revela-se bastante importante. Conforme se verá adiante, o reenvio trata da possibilidade de se

${ }^{3}$ CORREIA, A. Ferrer. Lições de Direito Internacional Privado. 4. ed., v.1. Coimbra: Editora Almedina, 2006, p.31.

Revista Brasileira de Direito Internacional, Curitiba, v.7, n.7, jan./jun.2008 
levar em consideração não apenas o direito material indicado pela regra de conflito do foro, mas também, o que determinam as regras de conflito deste ordenamento jurídico. Esta "possibilidade" é embasada por alguns princípios.

Os princípios de Direito Internacional são assim definidos por Jorge Miranda:

\begin{abstract}
Naturalmente, os princípios são mais gerais que as regras e, por isso, dotados de um menor grau de determinação e densificação. Encerrando sempre certo conteúdo valorativo, admitem, de ordinário, diversas modalidades de realização ou de concretização, contanto que preservado esse conteúdo essencial. Nem por isso, porém, deixam de obrigar, independentemente do grau de efectividade que, em cada momento, adquiram (e que, em Direito Internacional, poderia supor-se prima facie ser mais reduzido do que em Direito interno). ${ }^{4}$
\end{abstract}

Jacob Dolinger apresenta, na parte especial de seu curso de Direito Internacional Privado, antes de tratar especificamente dos contratos internacionais, consistente exposição acerca dos princípios de Direito Internacional Privado. ${ }^{5}$ Dentre as classes de princípios enunciados por Dolinger, merecem atenção, para o presente estudo, os princípios orientadores.

A efetividade, a harmonia e a uniformidade são arrolados por Dolinger como princípios orientadores. Referidos princípios revelam-se como vetores básicos para resolver conflitos de leis e são indispensáveis para que se possa compreender o reenvio. ${ }^{6}$

O princípio da efetividade veicula a idéia de necessidade de verificação se a decisão a ser proferida poderá contrariar a ordem pública da jurisdição executante, tornando a sentença inexeqüível. Desta forma, a efetividade é um princípio que pode levar a corte tanto a escolher outra lei, que não a potencialmente aplicável, quanto a declinar sua competência. ${ }^{7}$

\footnotetext{
${ }^{4}$ MIRANDA, Jorge. Curso de Direito Internacional Público. 3.ed. S. João do Estoril: Editora Princípio, 2006, p.121,122.

5 DOLINGER. Jacob. Direito Internacional Privado. v.2. Contratos e Obrigações no Direito Internacional Privado. Rio de Janeiro: Editora Renovar, 2007, p. 47.

6 DOLINGER. Jacob. Direito Internacional Privado. Contratos e Obrigações no Direito Internacional Privado. p. 106.

7 DOLINGER. Jacob. Direito Internacional Privado. Contratos e Obrigações no Direito Internacional Privado. p. 108.
}

Revista Brasileira de Direito Internacional, Curitiba, v.7, n.7, jan./jun.2008 
O princípio da harmonia, nas palavras de Ferrer Correia, responde à intenção primeira do direito de conflitos, que é assegurar a continuidade e a uniformidade de valoração das situações plurilocalizadas: "nenhum sistema positivo o pode ignorar, ele está na própria natureza das coisas. Ignorá-lo seria o mesmo que negar, pura e simplesmente, o Direito Internacional Privado".

De acordo com o princípio da harmonia deve ser o mesmo direito aplicável à determinada situação, independentemente de qual Estado aprecie a questão. $^{9}$

Como seria possível alcançar a harmonia jurídica internacional? Dário Moura Vicente apresentou em aula proferida na Faculdade de Direito da Universidade de Lisboa, Portugal, em março de 2007, três possibilidades: $i$. consagrando-se na legislação de cada país elementos de conexão comuns, ii. permitindo-se que o reenvio seja levado em consideração e iii. reconhecendose as sentenças estrangeiras, a litispendência internacional e a igualdade dos interessados. ${ }^{10}$ Destaque-se aí a importância do reenvio, objeto do presente estudo, como meio à assegurar o princípio da harmonia.

Registre-se o entendimento de Ferrer Correia, para quem são dois os propósitos que o Direito Internacional Privado responde: determinar a lei que deverá reger a situação privada internacional e executar essa tarefa de modo que a lei designada seja a tida por aplicável em todos os demais países. $\mathrm{O}$ primeiro propósito traz o princípio da efetividade, enquanto o segundo ressalta a importância do princípio da harmonia. ${ }^{11}$

Já o princípio da uniformidade é um princípio de Direito Internacional latu sensu, pois recomenda que as regras convencionais em geral devem ser interpretadas e aplicadas de maneira uniforme, sejam elas substantivas ou processuais, sejam relativas à temas de Direito Internacional Público ou Privado. ${ }^{12} \mathrm{~A}$ uniformidade recomenda que os tribunais decidam atentos à forma

\footnotetext{
${ }^{8}$ CORREIA, A. Ferrer. Lições de Direito Internacional Privado, p. 33.

9 PINHEIRO, Luís de Lima. Direito Internacional Privado. Introdução e Direito de Conflitos. Parte Geral, p. 239.

${ }^{10}$ VICENTE, Dário Moura. Aula de Direito Internacional Privado proferida em 05 março.2007 na Faculdade de Direito da Universidade de Lisboa, Portugal.

${ }_{11}$ CORREIA, A. Ferrer. Lições de Direito Internacional Privado, p. 506.

12 DOLINGER. Jacob. Direito Internacional Privado. Contratos e Obrigações no Direito Internacional Privado, p. 112.
}

Revista Brasileira de Direito Internacional, Curitiba, v.7, n.7, jan./jun.2008 
como a questão seria tratada em outro país e assim, veicula também o princípio da harmonia, acima mencionado.

Entendemos conveniente acrescentar aos princípios orientadores o princípio da proximidade que, atualmente, tem estado presente em grande parte das legislações estatais e convencionais de Direito Internacional Privado. ${ }^{13}$

O princípio da proximidade advém do direito norte-americano, que, na área dos contratos, consolidou o entendimento de que a lei aplicável deve ser a "most closely connected".

Para Dolinger, o princípio da proximidade é um princípio que "a rigor, poderia, sozinho, comandar a solução de todos os problemas no campo do conflito das leis". Para Luís de Lima Pinheiro trata-se de princípio que visa a aplicação do Direito com que os interessados estejam mais ligados ou familiarizados. Trata-se de um princípio de conteúdo indeterminado, vez que depende das especificidades da situação plurilocalizada. ${ }^{15}$

Os princípios orientadores assumem, portanto, relevante função, vez que determinam que o julgador fique atento à fatores que não dizem respeito apenas às questões relativas à aplicabilidade de uma ou outra lei, mas sim, às conseqüências desta aplicabilidade no âmbito internacional.

Referidas conseqüências devem ser analisadas a partir da forma como a lei do foro remete à lei estrangeira e dos mecanismos que utiliza para assegurar o princípio da efetividade, da harmonia, da uniformidade e da proximidade. Esta é a analise que se fará a seguir.

\section{REENVIO: CONCEITO E CARACTERÍSTICAS}

\footnotetext{
13 "Incorporado no Restatement 2nd on the Conflict of Laws (dos EUA), (o princípio da proximidade) foi posteriormente utilizado na Europa na Convenção de Roma sobre Direito Aplicável às Obrigações Internacionais, de 1984. Com isso, hoje tem uso corrente na maioria dos países europeus. Nas Américas o princípio também foi utilizado como regra de conexão na Convenção Interamericana sobre Direito Aplicável aos Contratos Internacionais, México, 1994." ARAUJO, Nadia. Direito Internacional Privado. Teoria e Prática Brasileira. 3.ed. Rio de Janeiro: Renovar, 2006, p. 17.

${ }^{14}$ ARAUJO, Nadia. Direito Internacional Privado. Teoria e Prática Brasileira, p. 17.

${ }^{15}$ LIMA PINHEIRO, Direito Internacional Privado. Introdução e Direito de Conflitos. Parte Geral. p. 243.
}

Revista Brasileira de Direito Internacional, Curitiba, v.7, n.7, jan./jun.2008 
sistema jurídico, através das regras de conflito, deve ser capaz de determinar qual a lei adequada para tutelar a relação jurídica plurilocalizada. Pode-se dizer, assim, que a determinação da lei aplicável é o objeto central do Direito Internacional Privado. ${ }^{16}$

A determinação da lei aplicável se dá através das regras de conflito (no Brasil, elas se encontram na Lei de Introdução ao Código Civil) que, através de um elemento de conexão, indicam uma lei potencialmente aplicável à relação jurídica internacional. O elemento de conexão é o núcleo da regra de conflito. ${ }^{17}$ Diz-se, portanto, que as normas de Direito Internacional Privado são normas indiretas, ou seja, normas que, através de um elemento de conexão, indicam qual será a lei material aplicável. As normas indiretas podem ser bilaterais,

${ }^{16}$ Cabe destacar que existem posicionamentos que incluem, no objeto da disciplina, questões relativas à nacionalidade e à condição jurídica do estrangeiro. Tal entendimento advém da escola francesa e é compartilhado por Jacob Dolinger, Clóvis Beviláqua e Haroldo Valladão. DOLINGER, Jacob. Direito Internacional Privado. 8.ed., v.1. Parte Geral. Rio de Janeiro: Editora Renovar, 2005 p. 3; BEVILÁQUA, Clóvis. Princípios Elementares de Direito Internacional Privado. 3.ed. Rio de Janeiro: Editora Freitas Bastos, 1938, p.125; VALLADÃO, Haroldo. Direito Internacional Privado. 4.ed., v.1. Introdução e Parte Geral. Rio de Janeiro: Editora Freitas Bastos, 1974, p. 44; citado por DOLINGER, Jacob. Direito Internacional Privado. Parte Geral, p. 2. A corrente anglo-saxã liga-se à idéia de que objeto do Direito Internacional Privado limita-se ao conflito de leis. Eduardo Espínola, Amílcar de Castro e Nadia de Araujo filiam-se a este posicionamento. Nadia de Araujo complementa, que, neste sentido, três perguntas fundamentais merecem ser respondidas: a) em que local acionar (conflito de jurisdição), b) qual a lei aplicável (método conflitual) e c) como executar atos e decisões estrangeiras (questões relativas ao reconhecimento das decisões proferidas pela justiça estrangeira). ESPÍNOLA, Eduardo. Elementos de Direito Internacional Privado. Rio de Janeiro: Editora Jacintho Ribeiro dos Santos, 1925, p. 23; CASTRO, Amílcar. Direito Internacional Privado. 3.ed. Rio de Janeiro: Editora Forense, 1977, p. 55; in DOLINGER, J. Direito Internacional Privado. Parte Geral, p. 2. ARAUJO, Nadia de. Direito Internacional Privado. Teoria e Prática Brasileira, p. 32.

${ }^{17}$ Têm-se, por exemplo, como elementos de conexão, a nacionalidade, o domicílio e o local da coisa. A escolha do elemento de conexão para determinadas matérias obedece à critérios de política legislativa. Países em que a população é formada, em sua maioria, por emigrantes, tendem a adotar como elemento de conexão para grande parte das situações a lei da nacionalidade do indivíduo. Entende-se que a lei nacional, além de ser mais adequada, é estável e certa, ou seja, imutável e determinada. A intenção é tentar manter os nacionais que deixaram o país sob a proteção de sua lei nacional. Por sua vez, países em que grande parte da população é imigrante tendem a optar pela escolha da lei do domicílio. É o caso do Brasil. Entende-se que a lei do domicílio é capaz de atender adequadamente aos interesses do imigrante vez que o mesmo conhece melhor a legislação do país em que vive e trabalha do que a de sua pátria. Para além disso, busca-se tutelar os interesses de terceiros que contratam e convivem com os imigrantes, que não teriam como saber especificidades acerca da lei nacional destes. $O$ interesse do Estado é integrar os estrangeiros que vivam em seu meio de modo definitivo. A aplicação da lei do domicilio, além de ser capaz de facilitar esta assimilação, proporciona a coincidência entre a competência jurisdicional com a competência legal: o juiz aplicará sua própria lei, a lei que efetivamente conhece, e não a lei estrangeira, sobre a qual haveria maior dificuldade de interpretação. DOLINGER, Jacob. Direito Internacional Privado. Parte Geral, p. 229, 230.

Revista Brasileira de Direito Internacional, Curitiba, v.7, n.7, jan./jun.2008 
quando indicam uma legislação estrangeira, ou unilaterais, quando determinam a aplicabilidade de sua própria lei. ${ }^{18}$

A aplicação, pelo juiz do foro, de uma lei estrangeira, invocada pela escolha das partes ou pela regra de conflitos, traz uma série de discussões. Primeiramente, há a questão de como o direito estrangeiro deve ser considerado pelo juiz do foro, se como fato (sendo condicionado à invocação da parte interessada) ou como lei (devendo ser aplicado de ofício pelo juiz, a partir da análise do que dispõe a regra de conflitos do foro). O Brasil entende o direito estrangeiro como lei. ${ }^{19}$

Partindo-se da idéia de que a aplicação da lei estrangeira não está condicionada a invocação pela parte interessada, há que se analisar se a remissão, feita de ofício pelo juiz do foro, que se faz ao direito estrangeiro, engloba apenas as normas de seu direito material ou também as regras de conflito estrangeiras.

Neste sentido a aplicação da lei estrangeira encontra alguns questionamentos.

Quanto a aplicação das normas substantivas, de direito material estrangeiras, há a questão de que possam ofender a ordem pública internacional ou contrariar as disposições imperativas da lei do foro, por exemplo. $^{20}$

\footnotetext{
${ }^{18}$ VALLADÃO, Haroldo. Direito Internacional Privado. Introdução e Parte Geral, p. 217.

${ }^{19}$ O Art. 337 do Código de Processo Civil determina que a invocação do direito estrangeiro pela parte interessada não é requisito para que a lei estrangeira seja aplicada. O juiz pode, no entanto, determinar que se prove sua vigência, se assim entender necessário: "Art. 337. A parte, que alegar direito municipal, estadual, estrangeiro ou consuetudinário, provar-lhe-á o teor e a vigência, se assim o determinar o juiz." BRASIL, Código de Processo Civil. Vade Mécum. Saraiva: 2008, p. 424. O Art. 14 da Lei de Introdução ao Código Civil Brasileiro, de 1942, assim também determina: "Art. 14 Não conhecendo a lei estrangeira, poderá o juiz exigir de quem a invoca prova do texto e da vigência." BRASIL, Lei de Introdução ao Código Civil. Vade Mécum. Saraiva: 2008, p. 165.

${ }^{20} \mathrm{~A}$ ordem pública internacional pode ser encarada como uma reserva. O que está em causa é o resultado à que conduz a aplicação de uma lei estrangeira à determinada relação jurídica internacional. A ordem pública visa garantir que as leis estrangeiras não sejam aplicadas no foro se conduzirem a um resultado que ofenda seus princípios fundamentais. Jacob Dolinger atribui à três juristas à fundamentação do princípio da ordem pública internacional na era moderna: Joseph Story, Friedrich Carl von Savigny e Pasquale Stanislao Mancini. DOLINGER. Jacob. Direito Internacional Privado. Contratos e Obrigações no Direito Internacional Privado,p. 115. A noção de ordem pública internacional diferencia-se da idéia trazida pelas normas imperativas. As normas imperativas, também denominadas, lois d'application immédiate, lois d'application nécessaire ou lois de police, são normas que, pelo conteúdo e função que exercem e pelo objeto que perseguem no ordenamento jurídico do foro, requerem aplicação
}

Revista Brasileira de Direito Internacional, Curitiba, v.7, n.7, jan./jun.2008 
Em contrapartida, caso se considere que a regra de conflitos, ao remeter à lei estrangeira, invoca não apenas as normas de direito material, mas também as normas de conflito estrangeiras (posicionamento rechaçado pelo ordenamento jurídico brasileiro) algumas implicações merecem ser estudadas. Esta forma de remissão poderá acarretar na aplicação de uma terceira lei ou até mesmo na devolução da resolução da situação privada internacional à lei do foro: é o que se denomina "reenvio".

\section{O REENVIO NO DIREITO INTERNACIONAL PRIVADO BRASILEIRO: A LEI DE INTRODUÇÃO AO CÓDIGO CIVIL}

A Lei de Introdução ao Código Civil Brasileiro, instituída pelo Decreto Lei $\mathrm{n}^{\circ}$ 4657, de 4 de setembro de 1942, proíbe expressamente o reenvio:

Art. 16. Quando, nos termos dos artigos precedentes, se houver de aplicar a lei estrangeira, ter-se-á em vista a disposição desta, sem considerar-se qualquer remissão por ela feita a outra lei. ${ }^{21}$

O Art. 16 é uma tradução literal do Art. 30 das Disposições sobre as Leis em Geral do Código Civil italiano de 1942, já alterado, em 1995, para expressamente aceitar o reenvio. ${ }^{22}$ Conveniente a crítica feita por Serpa Lopes: "a questão não poderia ter sido riscada pela forma radical exarada pelo Art. 16. Essa tradução literal não obedeceu a um prévio e cuidadoso exame crítico da matéria". 23

imediata. Enquanto na ordem pública internacional o que está em causa é o resultado da aplicação de certa lei, nas normas imperativas o que se pretende é a não frustração do objeto e da finalidade por elas visado. "As normas imperativas de Direito Internacional Privado são aquelas regras de âmbito interno que contém determinados assuntos considerados essenciais ao país que as promulgou e, por isso, são automaticamente aplicadas. Diante de casos conectados a ordenamentos jurídicos de mais de um país, elas tem o poder de afastar a busca pela legislação aplicável através do método conflitual, e assim, evitar o uso do direito estrangeiro, sendo aplicadas de imediato." FRIEDRICH, Tatyana Scheila. Normas Imperativas de Direito Internacional Privado. Lois de Police. Belo Horizonte: Editora Fórum, 2007.p. 25.

${ }^{21}$ BRASIL, Código Civil. Vade Mécum. Saraiva: 2008, p. 165.

22 DOLINGER, Jacob. Direito Internacional Privado. Parte Geral, p. 358.

${ }^{23}$ SERPA LOPES, Miguel Maria de. Comentário Teórico e Prático da Lei de Introdução ao Código Civil, vol. 1. Rio de Janeiro: Livraria Jacinto, 1943-1946, p. 392. Citado por VALLADÃO, Haroldo. Direito Internacional Privado. Introdução e Parte Geral, p. 229.

Revista Brasileira de Direito Internacional, Curitiba, v.7, n.7, jan./jun.2008 
Em que pese a atual Lei de Introdução ao Código Civil brasileiro proibir a ocorrência de reenvio, grande parte da doutrina e da jurisprudência brasileiras sempre se manifestaram a favor de sua aceitação, principalmente antes de 1942, quando vigorava a Lei de Introdução ao Código Civil de 1917, que era omissa quanto a admissibilidade ou não do reenvio.

Haroldo Valladão advogou ininterruptamente a favor do reenvio, tanto é que, em 1929, em sua dissertação para a livre docência de Direito Internacional Privado da Faculdade de Direito da Universidade do Rio de Janeiro, tratou especificamente da "Devolução nos Conflitos sobre a Lei Pessoal". ${ }^{4}$ Para Valladão:

... a referência, a devolução, à outra lei, é a vocação própria da norma de Direito Internacional Privado. É o raciocínio normal, em desenvolvimento espontâneo da determinação inicial do foro para que seja atingida a respectiva finalidade. Proibi-la e, absolutamente, qual fez o Art. 16 da Lei de Introdução, levará, ainda , às mais brandas injustiças... ${ }^{25}$

De acordo com Clóvis Beviláqua: "se a questão ainda se não pode considerar decidida, as mais poderosas razões, quer de lógica e doutrina, quer de autoridade e de lei, dão fortíssimo apoio à teoria do retorno". ${ }^{26}$

Quanto aos posicionamentos contrários à adoção do reenvio na doutrina brasileira, destaque-se o trazido por Oscar Tenório, que assim expõe seu entendimento:

As regras sobre conflitos de leis tem uma função primacial, mas não exclusiva: adota-as cada Estado para escolher a lei a aplicar. Constitui desvirtuamento dessa função sustentar que as normas de direito internacional privado existem também como dispositivos a serem admitidos pelo juízo estrangeiro nos casos de referência à lei de outra soberania. $^{27}$

\footnotetext{
${ }^{24}$ VALLADÃO, Haroldo. A Devolução nos Conflitos sobre a Lei Pessoal. São Paulo: 1929. Citado por DOLINGER, Jacob. Direito Internacional Privado. Parte Geral, p. 355.

${ }^{25}$ VALLADÃO, Haroldo. A Devolução nos Conflitos sobre a Lei Pessoal. São Paulo: 1929.

Citado por DOLINGER, Jacob. Direito Internacional Privado. Parte Geral, p. 231.

${ }^{26}$ BEVILÁQUA, Clóvis. Princípios Elementares de Direito Internacional Privado, p. 146. Citado por DOLINGER, Jacob. Direito Internacional Privado. Parte Geral, p. 355.

${ }^{27}$ TENÓRIO, Oscar. Direito Internacional Privado, vol. 1. 10ª Edição. Rio de Janeiro: Freitas Bastos, 1970, p. 355.
} 
A recusa a aceitação do reenvio feita por Oscar Tenório está embasada no seguinte critério: respeito ao critério de valoração do legislador do foro. No entanto, o argumento não é capaz de afastar o problema da desarmonia internacional das soluções e talvez não se revele suficiente para rechaçar, por si só, toda a doutrina já construída em torno do reenvio e atualmente, já consagrada por grande parte das legislações de Direito Internacional Privado.

A atual Lei de Introdução ao Código Civil Brasileiro, por deixar de consagrar o reenvio e por adotar, em sua maioria, normas bilaterais rígidas (aquelas que indicam o direito aplicável à determinada situação através de um elemento de conexão, sem se preocupar com o resultado que a aplicação do direito estrangeiro poderá conduzir) ${ }^{28}$, pode não se revelar suficiente para tratar, por si só, de todas as situações privadas internacionais que se apresentem diante do ordenamento jurídico brasileiro.

A codificação do Direito Internacional Privado no Brasil não tem se restringido apenas à Lei de Introdução ao Código Civil, de 1942, mas também ao Código de Bustamante, de 1928, a algumas Convenções Interamericanas sobre Direito Aplicável, da OEA - Organização dos Estados Americanos, e às Convenções de Haia sobre os Aspectos Civis do Seqüestro de Menores, de 1980 e de Adoção Internacional, de 1993. ${ }^{29}$

Em que pese a existência de outras fontes normativas, a necessidade de reforma da Lei de Introdução é amplamente defendida pela doutrina ${ }^{30}$. Nadia de Araujo complementa: "enquanto se espera uma mudança na

\footnotetext{
${ }^{28}$ Para Nadia de Araújo, o único exemplo de uma norma material de Direito Internacional Privado brasileiro é o Art. 10 da LICC, que determina que à sucessão por morte deve ser aplicada a lei do país em que era domiciliado o de cujus. $O § 1^{\circ}$ enuncia uma preocupação: "a sucessão de bens de estrangeiros, situados no país, será regulada pela lei brasileira em benefício do cônjuge ou dos filhos brasileiros, ou de quem os represente, sempre que não lhes seja mais favorável a lei pessoal do de cujus." Assim, tem-se que a opção pelo direito brasileiro só ocorre se a norma estrangeira for menos benéfica que a lei brasileira. A idéia é também veiculada, nos mesmos termos, pelo Art. 5ㅜ, XXXI da Constituição Federal de 1988: ARAUJO, Nadia de. Direito Internacional Privado. Teoria e Prática Brasileira, p. 95.

${ }^{29}$ ARAUJO, Nadia de. Direito Internacional Privado. Teoria e Prática Brasileira, p. 96. DOLINGER, Jacob. Direito Internacional Privado. Parte Geral, p. 83.

${ }^{30}$ DOLINGER, Jacob. Direito Internacional Privado. Parte Geral, p. 325. VALLADÃO, Haroldo. Direito Internacional Privado. Introdução e Parte Geral,p. 182.
}

Revista Brasileira de Direito Internacional, Curitiba, v.7, n.7, jan./jun.2008 
legislação, resta o trabalho dos tribunais para modernizar o Direito Internacional Privado e tentar incorporar as novas tendências." ${ }^{11}$

No entanto, infelizmente, o panorama apresentado pela jurisprudência atual em matérias concernentes ao Direito Internacional Privado revela, em alguns casos, a ausência, principalmente pelos juízes de primeiro grau, de raciocínio elementar à análise de questões privadas internacionais. Diversos julgados confundem, por exemplo, normas de direito processual (relativas à competência) com normas de direito material (relativas ao direito aplicável). Acertadamente, referidas decisões tem sido reformadas, e os juízes tem sido "alertados" pelos tribunais de que podem (e devem, pois assim determina a Lei de Introdução ao Código Civil) aplicar a lei estrangeira. ${ }^{32}$

Talvez a pouca abrangência e a razoável insuficiência das normas de Direito Internacional Privado brasileiras contribua ao aparente desconhecimento da matéria por alguns aplicadores do Direito. Desta forma, não apenas quanto ao reenvio, mas também quanto às demais regras de conflito, é que se faz necessária a reforma de nossa Lei de Introdução ao Código Civil.

\section{OS PROJETOS DE REFORMA DA LEI DE INTRODUÇÃO AO CÓDIGO CIVIL BRASILEIRO}

Os estudos para se alterar a Lei de Introdução ao Código Civil não são recentes. Em 1964 Haroldo Valladão apresentou, depois de autorizado pelos Decretos 51.005/1961 e 1.490/1962, Anteprojeto oficial de reforma da Lei de Introdução ao Código Civil, que denominou de Lei Geral de Aplicação de

\footnotetext{
${ }^{31}$ ARAUJO, Nadia de. Direito Internacional Privado. Teoria e Prática Brasileira, p. 95.

32 Legislação estrangeira - Discussão sobre qual legislação deve ser aplicada no caso concreto, a estrangeira, objeto de eleição pelas partes, ou a brasileira - Contrato celebrado no estrangeiro com cláusula expressa de aplicação da legislação estrangeira - Validade - Por força de imposição da norma de direito internacional privado, é possível que seja aplicada uma lei estrangeira no Brasil, num dado caso concreto, e caberá ao órgão judicante averiguar se sua aplicabilidade não ofenderá os princípios de nossa organização política, jurídica e social, ou seja, a soberania nacional, a ordem pública ou os bons costumes - Decisão de primeiro grau que não apreciou as demais preliminares - Obrigatoriedade, entretanto, de ser examinada a preliminar de inépcia da inicial - Prova pericial prejudicada - Recurso provido em parte, na parte conhecida. (Agravo de Instrumento no 1247070700. Rel. Des. Beretta da Silveira. j. 12/12/2003. Disponível em http://esaj.tj.sp.gov.br. Acesso em 30.out.2009).
}

Revista Brasileira de Direito Internacional, Curitiba, v.7, n.7, jan./jun.2008 
Normas Jurídicas. Após a análise da Comissão Revisora, formada pelo Ministro Luiz Gallotti, do Supremo Tribunal Federal, pelo Desembargador do Tribunal de Justiça do Estado da Guanabara, Oscar Tenório e por Valladão, a denominação "Lei Geral" foi substituída por "Código" e foram feitas outras alterações, algumas na redação e outras na substância. ${ }^{33}$

O Projeto de Código de Aplicação das Normas Jurídicas, mantendo a redação do Anteprojeto, consagra o reenvio ${ }^{34}$. $\mathrm{O}$ art. 78 assim determina:

Art. 78. Na observância do direito estrangeiro declarado competente, o juiz brasileiro atenderá às disposições do mesmo direito sobre a respectiva aplicação, inclusive a referência a outro direito com base em critério diferente, religião, raça, origem, naturalidade, nacionalidade, domicílio, vizinhança, residência, território, etc.

Parágrafo único. A referência acima só ficará excluída se não for feita ao direito brasileiro ou se não for feita a qualquer outro direito que afinal a aceite. ${ }^{35}$

O caput do Art. 78 determina a adoção da tese da referência global: a remissão à lei estrangeira engloba as suas regras de Direito Internacional Privado. Consta também a preocupação com a remissão que se opera a ordenamentos jurídicos plurilegislativos (ordenamentos que contêm dentro de seu território ordens jurídicas locais diversas, onde vigoram legislações diferentes), o que representa a preocupação de se pensar a lei estrangeira em sua integralidade. O parágrafo único esclarece: a referência da regra de conflitos estrangeira pode ser feita à lei brasileira (reenvio de primeiro grau ou retorno) ou a uma terceira lei, desde que essa se considere competente (reenvio de segundo grau ou transmissão). Da leitura das duas hipóteses trazidas pelo parágrafo único, tem-se que a teoria da devolução simples ${ }^{36}$ parece ter sido adotada para o caso do retorno, com vistas a se evitar o círculo

\footnotetext{
${ }^{33}$ VALLADÃO, Haroldo. Direito Internacional Privado. Introdução e Parte Geral, p. 183.

${ }^{34} \mathrm{O}$ Art. 78 foi aprovado com ressalvas por Oscar Tenório, que, conforme já destacado, condena a adoção do reenvio. VALLADÃO, Haroldo. Direito Internacional Privado. Introdução e Parte Geral, p. 525.

${ }^{35}$ VALLADÃO, Haroldo. Direito Internacional Privado. Introdução e Parte Geral, p. 538.

${ }^{36}$ Segundo a teoria da devolução simples a remissão feita pela norma de conflitos do foro abrange as normas de conflito de ordem estrangeira, mas a devolução operada pela norma de conflitos estrangeira à lei do foro ou a transmissão feita à uma terceira lei deve ser entendida como uma referência material. Pode-se dizer, que "a devolução simples tem a vantagem de ser relativamente fácil de se aplicar e de evitar as situações de pingue-pongue perpétuo" PINHEIRO, Luís de Lima. Direito Internacional Privado, p. 367.
}

Revista Brasileira de Direito Internacional, Curitiba, v.7, n.7, jan./jun.2008 
vicioso. Quanto à transmissão, o legislador foi mais específico: sua possibilidade é admitida desde que a terceira lei do circuito se considere competente, evitando-se, assim, o reenvio ad infinitum.

O Art. 78 representa inegável evolução. A forma como orienta a aplicação do direito estrangeiro tenta contornar os problemas decorrentes da aplicação do reenvio e, consequentemente, da desarmonia internacional dos julgados.

Faz-se apenas uma ressalva quanto a expressão "direito estrangeiro declarado competente". O termo "competente" talvez não seja o mais adequado, pois remete à expressão análoga do processo civil e pode gerar entendimentos inadequados. Desta forma, entendemos que a expressão "lei estrangeira aplicável" pode se revelar mais apropriada.

O Projeto de Código de Aplicação das Normas Jurídicas é bastante minucioso. Está dividido em seis capítulos: $i$. Disposições Gerais sobre a Lei e outras Normas Jurídicas, ii. Disposições sobre Tratados e Convenções Internacionais e Decretos e Regulamentos, iii. Disposições de Direito Internacional Privado, iv. Disposições de Direito Intertemporal, v. Disposições sobre Computação de Prazos e vi. Disposições Gerais e Finais. Além da inserção do reenvio, procurou-se legislar quanto à lei aplicável de forma específica, a fim de considerar as especificidades de cada situação (personalidade, capacidade, casamento, divórcio, filiação, alimentos, direitos reais, obrigações, sucessões, dentre outros).

Para Valladão o Anteprojeto de sua Lei Geral de Aplicação de Normas Jurídicas "fugiu de uma orientação universalista e apriorística, sem cair em uma diretriz antinômica, nacionalista e casuísta, contendo, assim, quer regras plurilaterais, quer unilaterais". 37

Mais sintético que o Projeto de Haroldo Valladão, o Projeto de Lei no 4.905/1995 começou a ser elaborado em 1994, por uma comissão composta pelos professores Rubens Limongi França, da Universidade de São Paulo, Inocêncio Mártires Coelho, da Universidade de Brasília, por Jacob Dolinger, da Universidade Estadual do Rio de Janeiro e por João Grandino Rodas, também

${ }^{37}$ VALLADÃO, Haroldo. Direito Internacional Privado. Introdução e Parte Geral, p. 183.

Revista Brasileira de Direito Internacional, Curitiba, v.7, n.7, jan./jun.2008 
da Universidade de São Paulo e, à época, Consultor Jurídico do Ministério das Relações Exteriores. 38

O Projeto de Lei nº 4.905/1995 é dividido em três capítulos: i. Da Norma Jurídica em Geral, ii. Do Direito Intertemporal e iii. Do Direito Internacional Privado, este divido em quatro seções: $i$. Regras de Conexão, ii. Aplicação do Direito Estrangeiro, iii. Pessoas Jurídicas, iv. Cooperação Jurídica Internacional.

O Art. 15 do Projeto de Lei nº 4.905/1995 assim determina:

Art. 15. Reenvio - Se a lei estrangeira, indicada pelas regras de conexão desta lei, determinar a aplicação da lei brasileira, esta será aplicada.

$\S 1^{\circ}$. Se, porém, determinar a aplicação de lei de outro país, esta última somente prevalecerá se também estabelecer que é competente.

$\$ 2^{\circ}$. Caso a lei do terceiro país não se considerar competente, aplicarse-á a lei estrangeira inicialmente indicada pelas regras de conexão desta Lei. ${ }^{39}$

O caput do Art. 15 veicula a possibilidade de ocorrência do reenvio de primeiro grau ou retorno, através de devolução simples. O $\S 1^{\circ}$ admite a transmissão, desde que a terceira lei indicada se considere competente, pois, se assim não for, o $§ 2^{\circ}$ determina que se aplique apenas a lei inicialmente designada pelas regras de conflito brasileiras.

O Art. 15 do Projeto de Lei n 4905/1995, ao separar em parágrafos a hipótese do reenvio de primeiro grau ou retorno $\left(\S 1^{\circ}\right)$ e do reenvio de segundo grau ou transmissão $\left(\$ 1^{\circ}\right.$ e $\left.\S 2^{\circ}\right)$ apresenta-se um pouco mais "didático"que o Art. 78 do Projeto de Código de Aplicação das Normas Jurídicas de 1964. Para além disso, a redação do Art. 15 utiliza a expressão "aplicação da lei estrangeira" ao invés de "direito estrangeiro competente" o que, conforme já exposto, entendemos mais adequado.

\footnotetext{
38 DOLINGER, Jacob. Direito Internacional Privado. Parte Geral, p. 531.

${ }^{39}$ DOLINGER, Jacob. TIBURCIO, Carmen. Vade-Mécum de Direito Internacional Privado. Rio de Janeiro: Renovar, 1996, p. 27.
}

Revista Brasileira de Direito Internacional, Curitiba, v.7, n.7, jan./jun.2008 
Inegável é que ambos os projetos, ao adotarem a teoria da referência global, representam um desenvolvimento na maneira de se pensar a aplicação da lei estrangeira.

O Projeto de Código de Aplicação das Normas Jurídicas, de 1964, não obteve aprovação congressual. ${ }^{40}$ Jacob Dolinger, na conferência que proferiu no dia 21 de agosto de 2008, no $6^{\circ}$ Congresso Brasileiro de Direito Internacional, em Curitiba, Paraná, quando indagado sobre o destino do Projeto de Lei no 4.905/1995 respondeu que, após vários indicativos de que seria aprovado, inclusive com parecer favorável na Comissão de Constituição e Justiça da Câmara dos Deputados, o projeto foi "inexplicavelmente" retirado do Congresso pelo Poder Executivo. ${ }^{41}$

Passados quinze anos da elaboração do Projeto de Lei nº 4.905/1995, a discussão quanto a reforma da Lei de Introdução ao Código Civil merece e precisa ser retomada. Conforme observou Nadia de Araujo:

No Brasil as regras de Direito Internacional Privado precisam ser adequadas a sistemática constitucional a partir de 1988, e ainda aos cânones do Novo Código Civil, pois a Lei de Introdução ao Código Civil, principal fonte normativa de Direito Internacional Privado, de 1942, permanece inalterada. Sua metodologia clássica de Direito Internacional Privado - inspirada nos moldes do século XIX -, mostrase inadequada à complexidade e à diversidade do momento. ${ }^{42}$

Assim é porque, defenderemos, a seguir, não apenas a adoção do reenvio pelo ordenamento jurídico brasileiro, como também a adequação de nossa Lei de Introdução ao Código Civil a um pensamento jurídico retóricoargumentativo $^{43}$, apto a tutelar, com efetividade, as expectativas dos indivíduos envolvidos em relações jurídicas plurilocalizadas da atualidade.

\footnotetext{
${ }^{40}$ DOLINGER, Jacob. Contratos e Obrigações no Direito Internacional Privado, p. 497.

${ }^{41}$ Conferência intitulada "Provincianismo no Direito Internacional Privado Brasileiro", proferida em 21 de agosto de 2008 no 6ํ Congresso Brasileiro de Direito Internacional em Curitiba, Paraná.

${ }^{42}$ ARAUJO, Nadia de. Direito Internacional Privado. Teoria e Prática Brasileira, p. 22.

43 "O Direito Internacional Privado precisa dispor de uma metodologia que incorpore o viés de um pensamento retórico-argumentativo e não mais lógico sistemático ou formalista, próprio das concepções positivistas. (...) Esta metodologia não quer dizer a total ausência de normas de conflito, mas sim uma flexibilização do sistema existente, através de técnicas novas (...)" ARAUJO, Nadia de. Direito Internacional Privado. Teoria e Prática Brasileira, p. 17.
}

Revista Brasileira de Direito Internacional, Curitiba, v.7, n.7, jan./jun.2008 


\section{NECESSIDADE DE ADOÇÃO DO REENVIO}

Sopesados os argumentos até aqui traçados, resta uma última indagação: por que adotar o reenvio nas regras de conflito brasileiras? Seria ele um método indispensável ao adequado funcionamento de nosso Direito Internacional Privado? Cremos que sim.

A adoção do reenvio envolve considerar a integralidade da lei estrangeira indicada pela regra de conflitos ou escolhida pelas partes. Pressupõe que o julgador entenda a lei estrangeira, fazendo-lhe uma referência global, uma referência máxima. Deixar de considerar o que dispõe as regras de conflito estrangeiras é o mesmo, nas palavras de Clóvis Bevilaqua, que "amputar a lei estrangeira que a lei pátria mandou aplicar". ${ }^{44} \mathrm{E}$ como observou Haroldo Valladão:

É essa a diretriz normal e justa, que atende à finalidade da ordem e da justiça para o caso, acatando e respeitando a outra lei que se determinou fosse a mais apta para decidi-lo. Afastando-se, não considerando a outra lei em seu todo, o juiz foro altera-a, modifica-a, cria ele próprio "uma terceira lei" que não é mais a outra lei, pois cada legislação, cada direito, é um sistema, vivendo cada texto, cada lei, em função de outros, genéricos ou específicos, que o delimitam substancial, temporal e espacialmente. ${ }^{45}$

As dificuldades encontradas pela adoção do reenvio podem ser contornadas com o emprego da devolução simples, que deve ser expressamente prevista na redação de nossas regras de conflito. Necessário é também que a redação da regra que adote o reenvio, construa sobre ele um sistema híbrido, admitindo-o e negando-o conforme as características da situação apresentada.

A utilização do reenvio através de um sistema híbrido não deve ocorrer para que o Estado determine o método que Ihe for mais conveniente, mas sim, para construir um sistema que conduza a aplicação do direito estrangeiro de

\footnotetext{
${ }^{44}$ BEVILÁQUA, Clóvis. Princípios Elementares de Direito Internacional Privado, p. 146. Citado por VALLADÃO, Haroldo. Direito Internacional Privado. Introdução e Parte Geral, p. 231.

${ }^{45}$ VALLADÃO, Haroldo. Direito Internacional Privado. Introdução e Parte Geral, p. 231.
}

Revista Brasileira de Direito Internacional, Curitiba, v.7, n.7, jan./jun.2008 
forma a corresponder às expectativas dos indivíduos que integram a relação privada internacional.

O Direito Internacional Privado evolui para um pensamento universalista, em que há que se ter em mente que toda relação jurídica que ultrapassa a fronteira nacional exige que se encontre a lei mais apropriada para regê-la. A concepção unilateralista em que se procura sempre e a todo custo aplicar a lei do foro "é uma visão particularista, nacionalista, egoísta, introvertida, voltada a antigos conceitos de soberania". ${ }^{46}$

A adoção do reenvio deve, portanto, obedecer a um raciocínio retóricoargumentativo, próprio do Direito Internacional Privado contemporâneo, que deve estar atento ao princípio da uniformidade, da efetividade e, principalmente, da harmonia internacional dos julgados e da proximidade.

Para Dolinger a "aceitação do princípio da proximidade é o melhor sinal da vitória do universalismo sobre o unilateralismo-territorialismo". 47 Dolinger ainda considera que a idéia de proximidade poderia ser usada para todo o Direito:

Tudo no Direito seria a procura de uma norma-reguladora que seja a mais próxima ao fato, a fim de chegar o mais perto possível do que realmente seja justo, equânime, moralmente recomendável. O direito, que sempre soube não ser uma ciência exata, seria realmente a ciência da aproximação. Tão somente. Daí a justiça humana ser falha. ${ }^{48}$

A idéia de proximidade remete, ainda, às "regras de conteúdo orientado", que se preocupam com o resultado alcançado através do caminho percorrido pelas normas de conflito, e devem permear a adoção do reenvio como método efetivo, apto a conduzir à harmonia internacional dos julgados e apto a tutelar, da melhor forma possível, a relação jurídica plurilocalizada.

Nas palavras de Nadia de Araújo:

O Direito Internacional Privado, reduzido a um direito apenas de regras conflituais, fruto de um excessivo formalismo (com a norma de conexão atuando por um jogo pré-determinado e caprichoso) está

\footnotetext{
${ }^{46}$ DOLINGER, Jacob. Contratos e Obrigações no Direito Internacional Privado, p. 546.

47 DOLINGER, Jacob. Contratos e Obrigações no Direito Internacional Privado, p. 547.

${ }^{48}$ DOLINGER, Jacob. Contratos e Obrigações no Direito Internacional Privado, p. 545, 546.
}

Revista Brasileira de Direito Internacional, Curitiba, v.7, n.7, jan./jun.2008 
sendo superado pelos novos topoi (lugares comuns) criados, e pelas soluções substanciais e flexíveis... ${ }^{49}$

Defendemos, assim, a utilização do reenvio no ordenamento jurídico brasileiro como método necessário, frente à teoria da referência global, e como método condutor a um sistema flexível, alicerçado na necessidade da aplicação da lei apropriada para solucionar a situação multiconectada.

Nadia de Araújo novamente argumenta:

Continuar com o sistema de Direito Internacional Privado do século XIX, que não se preocupa com os resultados obtidos quando é preciso usar a regra de conexão, é correr o risco de ignorar os anseios da sociedade, dando-lhes as costas. ${ }^{50}$

As relações jurídicas internacionais, pela complexidade que assumem na atualidade, tendem à não se subsumirem integralmente às prescrições normativas. Assim, há que se levar em conta que o reenvio não se destina a ser um método exato e acabado. É um método que conduz e orienta, a fim de assegurar que, dentre as leis potencialmente aplicáveis, aplique-se a lei que conceda segurança aos envolvidos, que seja efetiva, e que aos interessados esteja ligada.

\section{CONCLUSÃO}

O reenvio representa apenas um dos passos necessários à tentativa de adequação do Direito Internacional Privado brasileiro ao crescimento das relações plurilocalizadas que tendem a reclamar, com maior freqüência, uma tutela adequada de nosso Poder Judiciário.

Assim, para que o reenvio possa ser considerado um método necessário e eficiente, podemos concluir que precisamos: $i$. partir de uma referência global, de uma referência máxima ao ordenamento jurídico estrangeiro através de nossas regras de conflito, e, assim, ii. observar o que dispõe as normas de Direito Internacional Privado estrangeiras, para iii. aceitar

\footnotetext{
${ }^{49}$ ARAUJO, Nadia de. Direito Internacional Privado. Teoria e Prática Brasileira, p. 16.

${ }^{50}$ ARAUJO, Nadia de. Direito Internacional Privado. Teoria e Prática Brasileira, p. 11.
}

Revista Brasileira de Direito Internacional, Curitiba, v.7, n.7, jan./jun.2008 
o reenvio de primeiro grau ou retorno e o reenvio de segundo grau ou transmissão, através da iv. reforma de nossa Lei de Introdução ao Código Civil, que deverá construir um sistema híbrido, que analise as particularidades das relações plurilocalizadas, de modo a $v$. aplicar a lei que esteja mais ligada aos interessados e vi. buscar a harmonia internacional dos julgados.

É preciso que se crie, portanto, entre os operadores do Direito, um raciocínio que trabalhe com as normas de Direito Internacional Privado, que busque compreender a lei estrangeira em sua integralidade e que entenda que ela pode ser aplicada, se assim determinarem as regras de conflito. A partir daí, "para se evitar que a escolha seja meramente mecânica, "cega" aos valores de justiça material, "neutra" ou indiferente ao conteúdo das normas materiais encontradas" ${ }^{51}$, é que poderemos discutir as questões referentes à reserva da ordem pública internacional, das normas imperativas e das especificidades do âmbito do direito material de determinadas situações (consumidores e trabalhadores, por exemplo).

Desta forma, entendemos o estudo do reenvio como indispensável ao entendimento do funcionamento do Direito Internacional Privado. Ele pressupõe que se conduza a determinação da lei aplicável de uma forma ampla, atenta e não indiferente. É um método que se destina a orientar e viabilizar aplicação da lei que seja adequada a tutelar com efetividade as expectativas dos interessados. Um instrumento valioso para o qual talvez apenas não estejamos atentos.

A discussão quanto a reforma da Lei de Introdução ao Código Civil precisa ser retomada. Devemos adequá-la à Constituição Federal de 1988, ao Código Civil de 2002 e à um Direito Internacional Privado dialético, comprometido e eficaz. Um Direito Internacional Privado que seja universalista, que vise à harmonia internacional dos julgados e que constitua um meio apto à aplicação da lei apropriada à relação multiconectada. Um Direito Internacional Privado que envie e reenvie, e que assim, possibilite, aproxime e assegure.

${ }^{51}$ ARAUJO, Nadia de. Direito Internacional Privado. Teoria e Prática Brasileira, p. 19.

Revista Brasileira de Direito Internacional, Curitiba, v.7, n.7, jan./jun.2008 


\section{REFERÊNCIAS}

ARAUJO, Nadia. Direito Internacional Privado. Teoria e Prática Brasileira. 3.ed.Rio de Janeiro: Renovar, 2006.

BEVILÁQUA, Clóvis. Princípios Elementares de Direito Internacional Privado. 3.ed. Rio de Janeiro: Editora Freitas Bastos, 1938.

BRASIL, Código de Processo Civil. In Vade Mecum. 5.ed. São Paulo: Editora Saraiva, 2008.

BRASIL, Lei de Introdução ao Código Civil. In Vade Mecum. 5.ed. São Paulo: Editora Saraiva, 2008.

CASTRO, Amílcar. Direito Internacional Privado. 3.ed. Rio de Janeiro: Editora Forense, 1977.

CONGRESSO BRASILEIRO DE DIREITO INTERNACIONAL, 6., 2008, Curitiba. Provincianismo no Direito Internacional Privado Brasileiro.

DOLINGER, Jacob. Conferência proferida em 21 de agosto de 2008. Curitiba: Academia Brasileira de Direito Internacional, 2008.

CORREIA, A. Ferrer. Lições de Direito Internacional Privado. 4. ed., v.1. Coimbra: Editora Almedina, 2006.

DOLINGER, Jacob. Direito Internacional Privado. 8.ed., v.1. Parte Geral. Rio de Janeiro: Editora Renovar, 2005.

DOLINGER. Jacob. Direito Internacional Privado. v.2. Contratos e Obrigações no Direito Internacional Privado. Rio de Janeiro: Editora Renovar, 2007.

DOLINGER, Jacob. TIBURCIO, Carmen. Vade Mecum de Direito Internacional Privado. Rio de Janeiro: Renovar, 1996.

ESPÍNOLA, Eduardo. Elementos de Direito Internacional Privado. Rio de Janeiro: Editora Jacintho Ribeiro dos Santos, 1925.

Revista Brasileira de Direito Internacional, Curitiba, v.7, n.7, jan./jun.2008 
FRIEDRICH, Tatyana Scheila. Normas Imperativas de Direito Internacional Privado. Lois de Police. Belo Horizonte: Editora Fórum, 2007.

MIRANDA, Jorge. Curso de Direito Internacional Público. 3.ed. S. João do Estoril: Editora Princípio, 2006.

PINHEIRO, Luís de Lima. Direito Internacional Privado. 3. ed., v.1. Parte Geral. Coimbra: Editora Almedina, 2006.

TENORIO, Oscar. Direito Internacional Privado. 10.ed., v.1.Rio de Janeiro: Editora Freitas Bastos, 1970.

VALLADÃO, Haroldo. Direito Internacional Privado. 4.ed., v.1. Introdução e Parte Geral. Rio de Janeiro: Editora Freitas Bastos, 1974.

VICENTE, Dário Moura. Aula de Direito Internacional Privado proferida em 05.mar.2007. Faculdade de Direito da Universidade de Lisboa, Portugal. 